ISSN: 1410-8917

Jurnal Kimia - Sains \& Aplikasi

e-ISSN: 2597-9914

\section{Jurnal Kimia Sains dan Aplikasi} Journal of Scientific and Applied Chemistry

Journal homepage: http://ejournal.undip.ac.id/index.php/ksa

\title{
Silica Magnetite Adsorbent: Effect of Drying Temperature of Silica Sol Gel on Magnetite Core Structure
}

\author{
Endang Sawitri ${ }^{a}$, Choiril Azmiyawati ${ }^{a^{*}}$, Parsaoran Siahaan $^{\mathrm{a}}$ \\ a Chemistry Department, Faculty of Sciences and Mathematics, Diponegoro University, Jalan Prof. Soedarto, Tembalang, Semarang \\ * Corresponding author: choiril.azmiyawati@live.undip.ac.id
}

https://doi.org/10.14710/jksa.21.3.149-154

\begin{tabular}{l} 
Article Info \\
\hline Article history: \\
Received: 9 July 2018 \\
Revised: 25 July 2018 \\
Accepted: 30 July 2018 \\
Online: 31 July 2018 \\
\hline Keywords: \\
magnetite; coating \\
silica; sol gel; magnetic \\
extraction; drying \\
effect
\end{tabular}

\begin{tabular}{l}
\hline \\
\hline Kata Kunci: \\
magnetit; pelapisan \\
silika; sol gel; ekstraksi \\
magnetik; pengaruh \\
pengeringan
\end{tabular}

\section{Abstrak}

\begin{abstract}
Recently, magnetite was investigated as water purification adsorbent because it's unique magnetic properties that improved the adsorption efficiency through desorption process. But magnetite oxidized into maghemite/hematite with the increase of temperature. This transformation should be avoided to maintain the magnetic properties of magnetite. In this research magnetite separated from iron sand by magnetic extraction then coated with silica via sol gel method. The effect of drying temperature in sol gel had change the magnetite core structure into maghemite and found no formation of hematite at $350^{\circ} \mathrm{C}$. Silica coating proved had protected magnetite from transformation into hematite due to drying temperature until $350^{\circ} \mathrm{C}$.
\end{abstract}

Saat ini magnetit merupakan material yang banyak diteliti sebagai adsorben pemurnian air karena material ini memiliki sifat unik berupa sifat magnetis yang dapat meningkatkan efisiensi adsorsi melalui proses desorpsi. Magnetit teroksidasi menjadi meghemit/hematit seiring peningkatan suhu. Transformasi ini harus dihindari untuk menjaga sifat magnetis magnetit. Dalam penelitian ini magnetis dipisahkan dari pasir besi dengan ekstraksi magnetis kemudian dilapisi dengan silika melalui metode sol gel. Pengaruh suhu temperatur dalam sol gel merubah struktur core magnetit menjadi maghemit dan tidak ditemukan terbentuknya hematit sampai suhu $350^{\circ} \mathrm{C}$. Pelapisan silika terbukti mampu melindungi magnetit dari transformasi menjadi hematit selama pengeringan sampai suhu $350^{\circ} \mathrm{C}$

\section{Introduction}

Magnetit dikenal sebagai oksida besi hitam atau ferit oksida yang memiliki sifat magnetisme paling kuat [1]. Magnetit sebagai material magnetis memiliki kemampuan regenerasi/desorpsi yang baik dimana hanya dibutuhkan bantuan medan magnet eksternal sehingga proses regenerasi menjadi mudah karena tanpa pemanasan, penyaringan maupun sentrifugasi. Maka material ini banyak dipelajari dalam pengembangan adsorben pada pemurnian air karena meningkatkan efisiensi pemisahan limbah organik, ion anorganik anionik, sampai penghilangan bakteri [2, 3].

Indonesia kaya akan magnetit alam mengingat tersedianya yang melimpah dari pasir pantai [4]. Pasir besi pantai biasanya mengandung Magnetit $\left(\mathrm{Fe}_{3} \mathrm{O}_{4}\right)$, hematit $\left(\mathrm{Fe}_{2} \mathrm{O}_{3}\right)$, magnetit besi magnesium kromium oksida $\quad(\mathrm{Fe}, \mathrm{Mg})(\mathrm{Cr}, \mathrm{Fe})_{2} \mathrm{O}_{4} \quad$ [5], titanomagnetit 
$\left[\mathrm{xFe}_{2} \mathrm{TiO}_{4}(1-\mathrm{x}) \mathrm{Fe}_{3} \mathrm{O}_{4}\right]$ dan titanohematit [ $\mathrm{xFeTiO}_{3}(1-\mathrm{x}) \mathrm{Fe}_{2} \mathrm{O}_{3}$ ] [4] serta mineral seperti $\mathrm{SiO}_{2}, \mathrm{CaO}$, $\mathrm{MgO}, \mathrm{Cr}_{2} \mathrm{O}_{3}, \mathrm{Al}_{2} \mathrm{O}_{3}$ dan lain sebagainya [6]. Pemisahan secara magnetik dipilih untuk mendapatkan magnetit berkualitas dari pasir besi tersebut. Ekstraksi magnetis dapat memisahkan besi dari bijih dengan efisiensi hampir $100 \%$ (tergantung pada ukuran partikel, medan magnet dan kecepatan alir bahan) [7]. Teknik pemisahan magnetik menawarkan perspektif baru yang mempersiapkan magnetit yang lebih efisien dan hemat biaya dibandingkan dengan teknologi konvensional [7].

Magnetit memiliki sifat mudah teroksidasi oleh udara menjadi maghemit $\left(\gamma-\mathrm{Fe}_{2} \mathrm{O}_{3}\right)$ dan mencapai jumlah maksimum bila temperatur dinaikkan hingga $220^{\circ} \mathrm{C}$. Transformasi ini berlanjut sehingga dihasilkan hematit $\left(\alpha-\mathrm{Fe}_{2} \mathrm{O}_{3}\right.$ ) yang mencapai maksimum pada suhu $320^{\circ} \mathrm{C}[8$, 9]. Transformasi ini tentu akan merubah sifat fisik magnetit sebagai adsorben, oleh karena itu konversi ini menjadi pertimbangan penting dalam aplikasi magnetit sebagai adsorben. Dalam transformasi ini magnetit mengalami reaksi oksidasi sesuai dengan reaksi berikut:

$$
\mathrm{Fe}_{3} \dot{\mathrm{O}}_{4} \Longrightarrow \gamma \mathrm{Fe}_{2} \mathrm{O}_{3} \Longrightarrow \alpha \mathrm{Fe}_{2} \mathrm{O}_{3}
$$

Perubahan sifat magnetit ini tentu menjadi kelemahan magnetit sebagai adsorben mengingat sifat magnetisme magnetit yang sangat menguntungkan dalam proses desorpsi/regenerasi. Untuk mengatasi kelemahan ini magnetit harus dilindungi agar tidak mudah teroksidasi. Pelapisan dilakukan agar material ini menjadi lebih stabil, menghambat korosi, dan inert. Berbagai bahan pelapis magnetit telah banyak diaplikasikan tetapi material yang menjanjikan bagi perkembangan magnetit dan aplikasinya adalah silika [10] dan sol gel merupakan metode yang banyak dilakukan [11].

Prinsip dasar dari proses pelapisan silika dengan sol gel adalah transformasi gugus $\mathrm{Si}-\mathrm{O}-\mathrm{H}$ menjadi siloksan ( $\mathrm{Si}-\mathrm{O}-\mathrm{Si}$ ) melalui reaksi kondensasi [11]. Natrium silikat $\left(\mathrm{Na}_{2} \mathrm{SiO}_{3}\right)$ terhidrolisis menjadi asam silikat yang kemudian terkondensasi menjadi asam silikat dan lebih lanjut mengalami polikondensasi menjadi hidrogel seperti terlihat pada Gambar 1.

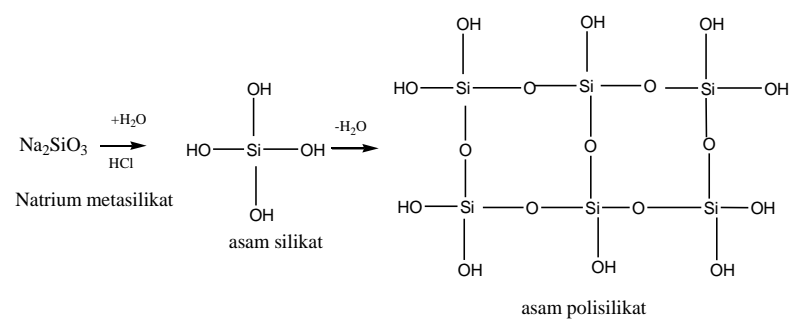

Gambar 1 Hidrolisis dan polikondensasi natrium metasilikat

Parameter yang berpengaruh terhadap proses sol gel adalah prekusor, $\mathrm{pH}$, katalis, temperatur pengeringan [12]. Pengeringan dilakukan untuk menambah kekerasan silika tetapi peningkatan suhu pada proses ini dapat mengoksidasi magnetit. Maka perlu dilakukan penelitian terhadap pengaruh suhu pengeringan terhadap perubahan struktur core magnetit.

Pada penelitian ini dilakukan sintesis magnetit silika dengan sumber magnetit alam dan perkusor natrium silika dengan menggunakan pada dua variasi suhu pengeringan yaitu tanpa kalsinasi $\left(80^{\circ} \mathrm{C}\right)$ dan dengan kalsinasi $\left(350^{\circ} \mathrm{C}\right)$. Magnetit alam hasil sintesis diuji dengan XRD dan dibandingkan dengan magnetit standar $\left(M_{s t d}\right)$. Keberhasilan pelapisan silika diuji dengan FTIR dan perubahan struktur magnetit sebelum dan sesudah pengeringan akan diuji dengan XRD.

\section{Metode Penelitian}

\section{Alat dan bahan}

Sebagai sumber magnetit digunakan pasir besi yang diambil dari pantai Klayar Pacitan. Pelapisan silika reagen proanalis menggunakan natrium silikat,natrium hidroksida,asam klorida dari Merck Damstat Jerman dan pelarutan dilakukan dengan aquades. Peralatan yang digunakan antara lain magnet permanen, oven Memmert, ayakan mesh, ball mill Retsch PM400, neraca analitik merk Ohause, magnetic stirrer merk Thermoline, furnace tipe FHX-25, FTIR 8201PC Shimadzu, dan XRD Shimadzu tipe 7000 .

\section{Sintesis magnetit dengan Ekstraksi Magnetis}

Ekstraksi magnetis merujuk pada metode yang digunakan oleh [13] dengan melakukan ekstraksi $\mathrm{Fe}_{3} \mathrm{O}_{4}$ dari pasir besi. Pasir besi diekstrak dengan magnet permanen untuk mendapatkan bahan yang tertarik oleh magnet yang paling kuat dengan pengulangan sebanyak 7 kali kemudian digerus dengan ball mill pada kecepatan 400 rpm selama 4 jam. Setelah proses miling, serbuk $\mathrm{Fe}_{3} \mathrm{O}_{4}$ dikeringkan menggunakan oven dengan temperatur $80^{\circ} \mathrm{C}$ selama 4 jam kemudian diayak dengan ayakan mesh.

\section{Pelapisan Magnetit dengan Silika}

Pelapisan magnetit dengan silika mengikuti metode dengan sedikit modifikasi seperti dilakukan oleh Zhao,2008 dengan sedikit perubahan sebagai berikut: Larutan natrium silikat $10 \%$ ditambahkan ke dalam serbuk $\mathrm{Fe}_{3} \mathrm{O}_{4}$ dan $\mathrm{pH}$ larutan diturunkan sampai 7 dengan penambahan $\mathrm{HCl} 3 \mathrm{M}$ selama 2 jam. Campuran diaduk selama 3 jam setelah penambahan. Rasio massa $\mathrm{Fe}_{3} \mathrm{O}_{4}$ dan $\mathrm{SiO}_{2}$ adalah 1:20. Setelah terbentuk gel , campuran dioven pada suhu $80^{\circ} \mathrm{C}$ selama 2 jam kemudian di aging selama 24 jam kemudian dicuci dengan aquadest sampai bersih dari ion klorida [14]. Endapan dibagi 2 untuk dikalsinasi pada suhu $350^{\circ} \mathrm{C}$ dalam furnace selama 3 jam dan dipanaskan pada oven suhu $80{ }^{\circ} \mathrm{C}$ selama 24 jam. Keberhasilan pelapisan magnetit dengan silika dilakukan dengan uji ketahanannya terhadap asam dengan merendam $200 \mathrm{mg}$ adsorben dengan $\mathrm{HCl} 2 \mathrm{~N}$ diaduk dengan magnetik stirrer dan diambil o,5 ml, ditambah 
dengan 1,10 fenantrolin, hidroksilamin hidroklorida, dan natrium asetat masing -masing $1 \mathrm{ml}$ lalu diencerkan hingga $10 \mathrm{ml}$ dan diuji dengan spektrometer UV Vis pada panjang gelombang $504 \mathrm{~nm}$. Uji dilakukan pada $1,2,3,4,5,6$ dan 24 jam.

\section{Karakterisasi}

Keberhasilan ekstraksi magnetit dan perubahan struktur core magnetit dikarakerisasi dengan X-ray Diffractometer (XRD) menggunakan radiasi $\mathrm{Cu}$ $\mathrm{K} \alpha$. Jarak antar kisi d dihitung dengan hukum Bragg dan data difaktogram dibandingkan dengan magnetit standar $\left(\mathrm{M}_{\text {std }}\right)$ menggunakan data dari web rruff.info nomor RRUFFID=R061111. Pelapisan silika diuji dengan FTIR pada panjang gelombang 400-4000 $\mathrm{cm}^{-1}$. Perubahan core magnetit diamati dengan membandingkan hasil difaktogram dan spektra FTIR sebelum dan sesudah pelapisan pada kedua variasi suhu yang digunakan.

\section{Hasil dan Pembahasan}

\section{Karakter Magnetit Hasil Ekstraksi Magnetis Pasir Pantai Klayar}

Hasil indentifikasi menggunakan difraksi sinar $\mathrm{X}$ diperoleh 3 buah puncak dominan yaitu pada sudut $2 \theta$ yaitu $30,0526^{\circ}, 35,3954^{\circ}$ dan $62,4231^{\circ}$. Puncak-puncak yang dominan tersebut dilakukan search macth pada www.webmineral.com, diperoleh jenis senyawa yang terkandung adalah Magnetit $\left(\mathrm{Fe}_{3} \mathrm{O}_{4}\right)$. Data difaktogram juga mendukung bahwa magnetit hasil pemisahan $\left(M_{0}\right)$ terbukti memiliki posisi dan intensitas relatif puncak difraksi yang sesuai dengan magnetit standar $\left(\mathrm{Fe}_{3} \mathrm{O}_{4}\right)$ (RRUFFID=Ro61111) seperti terlihat pada Gambar 2. Puncak karakteristik magnetit hasil ekstraksi identik dengan magnetit standar dengan nilai Indeks Miller (311), (440), (220), (400), dan (422) dengan jarak kisi atom (a) $=0,84053$. Difraktogram juga menunjukkan garis difraksi tajam yang menunjukkan magnetit dari pasir pantai Klayar ini memiliki tingkat kristalinitas yang tinggi. Perbandingan nilai d yang diperoleh untuk sampel juga bersesuaian dengan data difraksi magnetit standar pada Tabel 1.

Dilihat dari hasil difaktogram di atas ekstraksi magnetis terbukti mampu memisahkan magnetit dari komponen pasir pantai yang lain dengan sangat baik dan ekonomis karena tanpa membutuhkan bahan kimia maupun pemanasan.

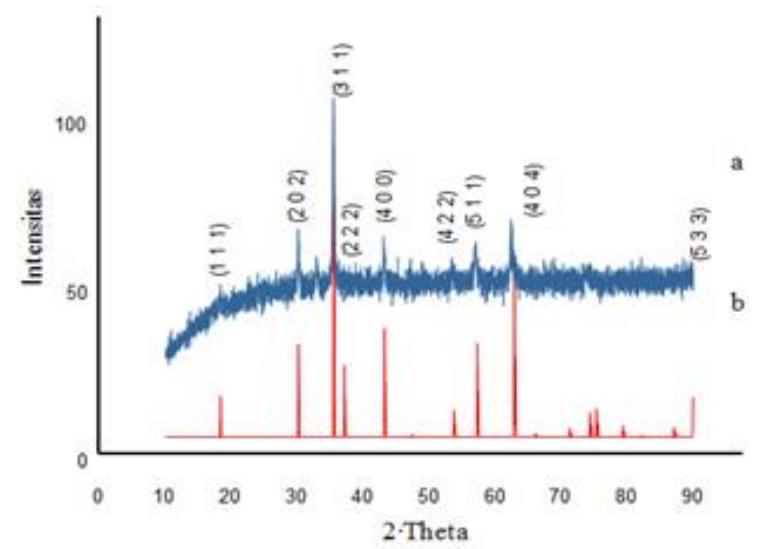

Gambar 2 Pola difraksi magnetit (a) hasil ekstraksi pasir pantai Klayar $\left(M_{0}\right)$ dan (b) magnetit standar $\left(M_{\text {std }}\right)$ ( Rruff ID=Ro61111)

\section{Pelapisan Core Magnetit dengan Silika}

Keberhasilan pelapisan silika terhadap core magnetit $\left(M_{0}\right)$, dilakukan dengan Fourier Transform Infra Red(FTIR) pada dua suhu pengeringan yaitu pada $80{ }^{\circ} \mathrm{C}\left(\mathrm{MSA}_{0}\right)$ dan $350^{\circ} \mathrm{C}\left(\mathrm{MSB}_{0}\right)$ menghasilkan spektra seperti terlihat pada Gambar 3. Kehadiran silika pada magnetit ditunjukkan oleh munculnya spektra kuat $\mathrm{SiO}_{2}$, meliputi tekuk simetris $\mathrm{Si}-\mathrm{O}-\mathrm{Si}$ pada $786 \mathrm{~cm}^{-1}$ dan $\mathrm{Si}-\mathrm{O}-\mathrm{H}$ pada $956 \mathrm{~cm}^{-}$ ${ }^{1}$. Diamati pula vibrasi tekuk dan regangan asimetris $\mathrm{Si}-$ $\mathrm{O}$-Si pada panjang gelombang $1095 \mathrm{~cm}^{-1}$ dan $1211 \mathrm{~cm}^{-1} \mathrm{dan}$ tambahan ada puncak lebar pada bilangan gelombang 3750-3200 dan $1627 \mathrm{~cm}^{-1}$ yang menunjukkan hadirnya gugus - $\mathrm{OH}$ pada silanol dan molekul air teradsorpsi [15]. Hadirnya magnetit ditandai dengan munculnya puncak Fe-O pada panjang gelombang $471 \mathrm{~cm}^{-1}[16]$

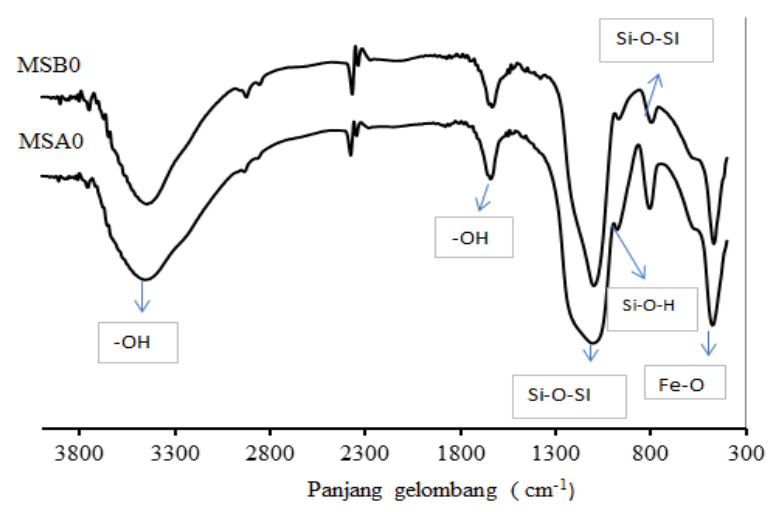

Gambar 3 Spektra FTIR yang mempresentasikan hasil pelapisan silika pada magnetit

Pengujian terhadap keberhasilan pelapisan silika di atas magnetit juga dilakukan dengan menguji ketahanan magnetit silika dalam larutan asam. Telah diketahui bahwa magnetit larut dalam kondisi asam, sedangkan silika amorf hampir tidak dapat larut. Ketahanan magnetit terhadap asam dapat dilihat dari banyaknya ion besi yang dapat dilarutkan oleh asam. Reaksi pengikisan magnetit dengan asam adalah sebagai berikut:

$$
\mathrm{Fe}_{3} \mathrm{O}_{4}+\mathrm{HCl} \rightarrow \mathrm{FeCl}_{3}+\mathrm{H}_{2} \mathrm{O}
$$




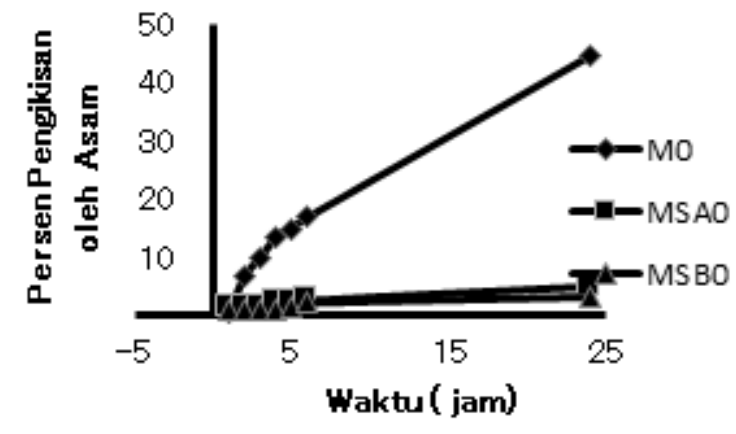

Gambar 4 Grafik Pengikisan Asam menggunakan $\mathrm{HCl}$ 2N pada $\mathrm{M}_{0}, \mathrm{MSA}_{0}, \mathrm{MSB}_{0}$

Hasil uji menunjukkan bahwa magnetit tanpa pelapisan larut dalam asam. Terlihat pada Gambar 4 magnetit tanpa pelapisan terkikis $45 \%$ sedangkan magnetit-silika dapat mempertahankan diri dari pengikisan. Adanya pengikisan (3 dan 5 persen) tampaknya berasal dari sebagian magnetit yang tidak terlapis sempurna terlihat dari prosentase pengikisan yang tidak bertambah secara signifikan pada 6 jam pertama.

Setelah proses leaching dengan asam selama 24 jam Magnetit terbukti dilindungi oleh pelapisan silika di permukaan yang memperlambat laju disolusi. Pengamatan ini menegaskan bahwa silika membentuk lapisan yang menutup permukaan partikel magnetit dengan membentuk gugus silanol dan siloksan seperti dikonfirmasi oleh data FTIR. Ilustrasi pelapisan ada pada.Gambar 5 .
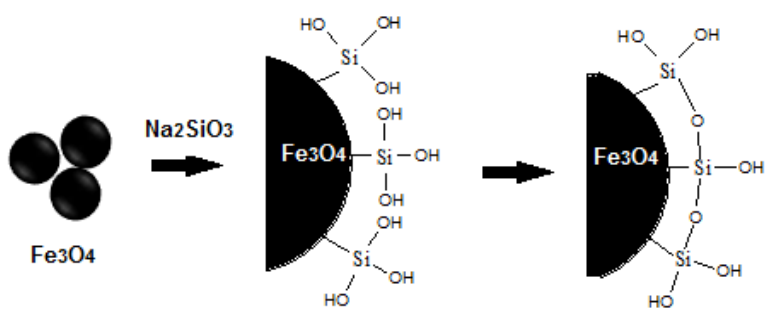

Gambar 5 Ilustrasi mekanisme pelapisan silika di atas magnetit

\section{Ketahanan Magnetit Terhadap Suhu Kalsinasi Silika}

Pengamatan secara visual terhadap oksida besi dapat secara signifikan digunakan sebagai bantuan dalam identifikasi. Hal ini juga bisa digunakan sebagai panduan praktis untuk uji kemurnian dalam beberapa kasus. Magnetit $\left(\mathrm{Fe}_{3} \mathrm{O}_{4}\right)$ berwarna hitam, maghemite $\left(\gamma^{-}\right.$ $\mathrm{Fe}_{2} \mathrm{O}_{3}$ ) berwarna coklat kemerahan, sedangkan hematit $\left(\alpha-\mathrm{Fe}_{2} \mathrm{O}_{3}\right)$ berwarna merah [9].

Magnetit yang dihasilkan dari ekstraksi magnetik adalah besi jet hitam $\left(M_{0}\right)$ sesuai dengan karakterisasi menggunakan XRD berupa magnetit. Tapi setelah setelah dilapisi silika dan dikalsinasi pada suhu $350^{\circ} \mathrm{C}$ selama 3 jam di udara, bubuk magnetit hitam itu berubah menjadi bubuk coklat merah tua $\left(\mathrm{MSB}_{0}\right)$. Itu tidak terjadi pada $\mathrm{MSA}_{0}$ yang merupakan magnetit silika yang tanpa kalsinasi (suhu pengeringan $80^{\circ} \mathrm{C}$ ) yang dapat mempertahankan warna hitam setelah pelapisan silika, seperti yang terlihat pada Gambar 6.

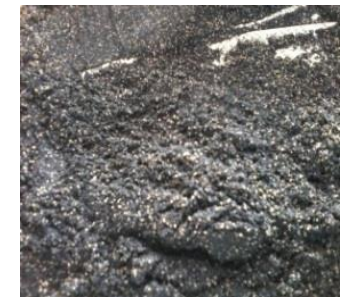

(a)

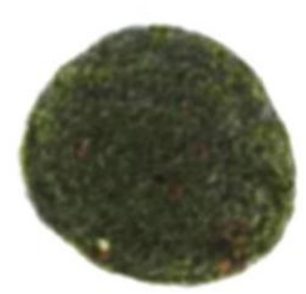

(c)

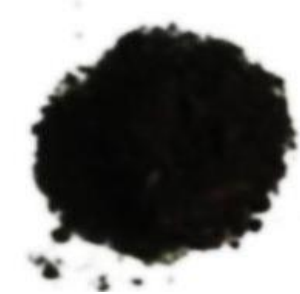

(b)

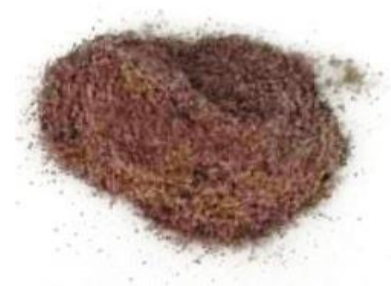

(d)
Gambar 6 (a) pasir pantai , (b) Mo (magnetit hasil ekstraksi magnetis sebelum pelapisan silika), (c) MSAo (magnetit setelah pelapisan silika tanpa kalsinasi $\left(80^{\circ} \mathrm{C}\right)$ ), and $(\mathrm{d}) \mathrm{MSB}$ magnetit setelah pelapisan silika dengan kalsinasi $\left(350^{\circ} \mathrm{C}\right)$ )

Pengaruh suhu pengeringan terhadap karakter magnetit setelah dilapisi silika dikonfirmasi dengan membandingkan difaktogram magnetit tanpa silika $\left(M_{0}\right)$ dan magnetit terlapisi silika pada dua variasi suhu yang digunakan ( $\mathrm{MSA}_{0}$ dan $\mathrm{MSB}_{0}$ ) dengan pola difaktogram magnetit standar (www.webmaterial.com). Diperoleh grafik puncak difaktogram $\mathrm{M}_{0}, \mathrm{MSA}_{\circ}$ dan $\mathrm{MSB}_{0}$ seperti terlihat pada Gambar 7. Dari puncak diaktogram terlihat bahwa magnetit tidak berubah kristalitasnya setelah dilapis silika pada suhu $80^{\circ} \mathrm{C}$ dan sedikit bergeser pada suhu $350^{\circ} \mathrm{C}$. Selain itu juga ditemukan puncak amorf pada sudut $2 \theta$ pada $20-25^{\circ}$ sebagai akibat penambahan struktur silika di atas magnetit [17].

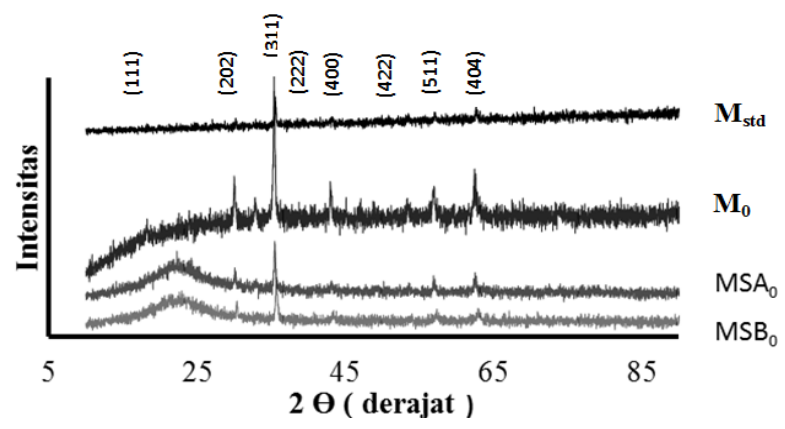

Gambar 7 Difaktogram Magnetit standar $\mathrm{M}_{0}, \mathrm{MSA}_{0}, \mathrm{MSB}_{0}$

Telaah terhadap pola difaktogram $\mathrm{MSA}_{0}$ ditemukan karakteristik puncak di $30,1^{\circ}(220) ; 35,5^{\circ}(311) ; 37,1^{\circ}$ (22); $43,1^{\circ}(400) ; 53,5^{\circ}(422) ; 57,0^{\circ}(511)$ dan $62,6^{\circ}$ (440), yang sesuai dengan pola $\mathrm{Fe}_{3} \mathrm{O}_{4}$ (Rruff ID=Ro61111). Sedangkan $\mathrm{MSB}_{0}$ memiliki karakteristik puncak pada 
$30,3^{\circ}(220) ; 35,7^{\circ}(311) ; 43,3^{\circ}(400) ; 53,8^{\circ}(422) ; 57,4^{\circ}$ (511) and $63^{\circ}(440)$ yang sesuai dengan pola maghemit. Fase magnetit dan maghemit memiliki pola XRD yang mirip dengan struktur kubik terlihat di data difaktogram pada Gambar 7, kecuali panjang sel satuannya (a). Hasil perhitungan d dan a dari berbagai sampel dan magnetit standar disajikan di tabel 1.

Tabel 1 Data XRD Magnetit Silika

\begin{tabular}{|c|c|c|c|c|c|}
\hline \multirow{2}{*}{ Partikel } & & \multicolumn{3}{|c|}{ Data Kisi Sel } & \multirow{2}{*}{$\begin{array}{l}\text { Fasa yang } \\
\text { terwakili }\end{array}$} \\
\hline & hkl & $2 \ominus$ & $\mathrm{d}(\mathrm{nm})$ & $a(\AA)$ & \\
\hline \multirow{3}{*}{ M std } & 311 & 35,473 & 2,53 & 8,396 & \multirow{3}{*}{$\begin{array}{c}\mathrm{Fe}_{3} \mathrm{O}_{4} \\
\text { magnetit }\end{array}$} \\
\hline & 440 & 62,611 & 1,48 & 8,396 & \\
\hline & 220 & 30,117 & 2,97 & 8,396 & \\
\hline \multirow{3}{*}{$M_{0}$} & 311 & 35,3954 & 2,53 & 8,404 & \multirow{3}{*}{$\begin{array}{c}\mathrm{Fe}_{3} \mathrm{O}_{4} \\
\text { magnetit }\end{array}$} \\
\hline & 440 & 62,4231 & 1,48 & 8,409 & \\
\hline & 220 & 30,0526 & 2,97 & 8,404 & \\
\hline \multirow{3}{*}{$\mathrm{MSA}_{0}$} & 311 & 35,4843 & 2,53 & 8,384 & \multirow{3}{*}{$\begin{array}{c}\mathrm{Fe}_{3} \mathrm{O}_{4} \\
\text { magnetit }\end{array}$} \\
\hline & 440 & 62,4733 & 1,48 & 8,403 & \\
\hline & 220 & 30,1688 & 2,96 & 8,372 & \\
\hline \multirow{3}{*}{$\mathrm{MSB}_{0}$} & 311 & 35,7142 & 2,51 & 8,331 & \multirow{3}{*}{$\begin{array}{l}{ }^{\curlyvee \mathrm{Fe}_{2} \mathrm{O}_{3}} \\
\text { maghemit }\end{array}$} \\
\hline & 220 & 30,3779 & 2,94 & 8,316 & \\
\hline & 440 & 62,9321 & 1,47 & 8,348 & \\
\hline
\end{tabular}

Paparan di atas membuktikan bahwa suhu pengeringan suhu $80^{\circ} \mathrm{C}$ tidak merubah struktur core magnetit, sedangkan pada suhu pengeringan $350^{\circ} \mathrm{C}$ terjadi perubahan struktur magnetit menjadi maghemit dan tidak ditemukan transformasi menjadi hematit. Pembentukan gugus silanol dan siloksan di atas magnetit yang terbentuk memberikan lapisan inert yang mencegah oksidasi. Pelapisan silika suhu $80^{\circ}$ terbukti dapat mencegah oksidasi magnetit menjadi hematit walau tidak dapat menghindari terbentuknya maghemit $\gamma$-Fe203 sampai suhu kalsinasi $350^{\circ} \mathrm{C}$. Hasil inimendukung hasil penelitian yang dilakukan Fajaroh, 2013 yang menyatakan bahwa partikel $\mathrm{Fe} 3 \mathrm{O} 4$ yang dilapisi silika teroksidasi menjadi $\curlyvee-\mathrm{Fe} 2 \mathrm{O} 3$ pada suhu maksimal 250270 oC dan selanjutnya dapat berubah menjadi $\alpha-\mathrm{Fe}_{2} \mathrm{O} 3$ pada suhu maksimal 300-320 oC [8].

\section{Kesimpulan}

Sifat magnetis sangat menguntungkan dalam proses desorpsi dengan memanfaatkan daya tarik partikel terhadap magnet permanen. Perubahan magnetit menjadi maghemit/hematit perlu dicegah agar tidak mempengaruhi sifat magnetis magnetit yang sangat menguntungkan dalam aplikasinya sebagai adsorben pemurnian air. Pengaruh suhu pengeringan tanpa kalsinasi terbukti dapat mempertahankan struktur magnetit sementara pada suhu pengeringan sampai $350^{\circ} \mathrm{C}$ terjadi perubahan struktur magnetit menjadi maghemit. Pelapisan magnetit dengan silika memberikan lapisan inert yang mampu mencegah oksidasi magnetit menjadi hematit walau tidak dapat menghindari terbentuknya maghnetit $\gamma$ - $\mathrm{Fe}_{2} \mathrm{O} 3$ sampai suhu kalsinasi $350^{\circ} \mathrm{C}$.

\section{Daftar Pustaka}

[1] Amyn S. Teja, Pei-Yoong Koh, Synthesis, properties, and applications of magnetic iron oxide nanoparticles, Progress in Crystal Growth and Characterization of Materials, 55, 1, (2009) 22-45 https://doi.org/10.1016/j.pcrysgrow.2008.08.003

[2] Ritu D. Ambashta, Mika Sillanpää, Water purification using magnetic assistance: A review, Journal of Hazardous Materials, 180, 1, (2010) 38-49 https://doi.org/10.1016/j.jhazmat.2010.04.105

[3] D. Harikishore Kumar Reddy, Yeoung-Sang Yun, Spinel ferrite magnetic adsorbents: Alternative future materials for water purification?, Coordination Chemistry Reviews, 315, (2016) 90-111 https://doi.org/10.1016/j.ccr.2016.01.012

[4] Agus Yulianto, Satria Bijaksana, Waloejo Loeksmanto, Comparative Study on Magnetic Characterization of Iron Sand from Several Locations in Central Java, Indonesian Journal of Physics, 14, 2, (2003) 63-66

[5] Bilalodin, Sunardi, Muhtar Effendy, Analisis Kandungan Senyawa Kimia dan Uji Sifat Magnetik Pasir Besi Pantai Ambal, Jurnal Fisika Indonesia, 17, 50, (2013) 29-31

[6] Dedi Sufiandi, Konsentrasi Pasir Besi Titan Dari Pengotornya Dengan Cara Magnetik, Metalurgi Majalah Ilmu dan Teknologi, 26, 1, (2015) 15-20 http://dx.doi.org/10.14203/metalurgi.v26i1.4

[7] Cafer T. Yavuz, Arjun Prakash, J. T. Mayo, Vicki L. Colvin, Magnetic separations: From steel plants to biotechnology, Chemical Engineering Science, 64, 10, (2009) 2510-2521 https://doi.org/10.1016/j.ces.2008.11.018

[8] Fauziatul Fajaroh, Heru Setyawan, Adrian Nur, I. Wuled Lenggoro, Thermal stability of silica-coated magnetite nanoparticles prepared by an electrochemical method, Advanced Powder Technology, 24, 2, (2013) 507-511 https://doi.org/10.1016/j.apt.2012.09.008

[9] Rochelle M. Cornell, Udo Schwertmann, The Iron Oxides: Structure, Properties, Reactions, Occurrences and Uses, Wiley, 2006.

[10]Aránzazu del Campo, Tapas Sen, Jean-Paul Lellouche, Ian J. Bruce, Multifunctional magnetite and silica-magnetite nanoparticles: Synthesis, surface activation and applications in life sciences, Journal of Magnetism and Magnetic Materials, 293, 1, (2005)

https://doi.org/10.1016/j.jmmm.2005.01.040

$33-40$

[11] Enobong R. Essien, Oluyemi A. Olaniyi, Luqman A. Adams, Rafiu O. Shaibu, Sol-Gel-Derived Porous Silica: Economic Synthesis and Characterization, Journal of Minerals and Materials Characterization and Engineering, 11, 10, (2012) 976-981 http://dx.doi.org/10.4236/jmmce.2012.1110098 
[12] C. A. Milea, C. Bogatu, A. DuŢ̆, The Influence of Parameters in Silica Sol-Gel Process, Bulletin of the Transilvania University of Brasov, Series I: Engineering Sciences, 4, 1, (2011) 59-66

[13] Henny Dwi Bhakti, Mashuri, Pengaruh Ukuran Partikel Fe3O4 Dari Pasir Besi Sebagai Bahan Penyerap Radar Pada Frekuensi X-Band dan KuBand, in, Institut Teknologi Sepuluh Nopember, Surabaya, 2014.

[14] Xiaoli Zhao, Yali Shi, Thanh Wang, Yaqi Cai, Guibin Jiang, Preparation of silica-magnetite nanoparticle mixed hemimicelle sorbents for extraction of several typical phenolic compounds from environmental water samples, Journal of Chromatography A, 1188, 2, (2008) 140-147

https://doi.org/10.1016/j.chroma.2008.02.069

[15] Samira Hozhabr Araghi, Mohammad H. Entezari, Mahmoud Chamsaz, Modification of mesoporous silica magnetite nanoparticles by 3aminopropyltriethoxysilane for the removal of $\mathrm{Cr}(\mathrm{VI})$ from aqueous solution, Microporous and Mesoporous Materials, 218, (2015) 101-111 https://doi.org/10.1016/j.micromeso.2015.07.008

[16] Damien Faivre, Iron Oxides: From Nature to Applications, Wiley, 2016.

[17] N. Mahmed, O. Heczko, A. Lancok, S. P. Hannula, The magnetic and oxidation behavior of bare and silicacoated iron oxide nanoparticles synthesized by reverse co-precipitation of ferrous ion $\left(\mathrm{Fe}_{2}+\right)$ in ambient atmosphere, Journal of Magnetism and Magnetic Materials, 353, (2014) 15-22 https://doi.org/10.1016/j.jmmm.2013.10.012 